\title{
Profile and outcomes of patients with acute complications of malaria presenting to an urban emergency department of a tertiary hospital in Tanzania
}

\author{
Raya Yusuph ${ }^{1,2^{*}}$, Hendry R. Sawe ${ }^{1,2}$, Paulina N. Nkondora ${ }^{1,2}$ and Juma A. Mfinanga ${ }^{1,2}$
}

\begin{abstract}
Objectives: In Tanzania, malaria ranks number three among the top ten causes of deaths in all age groups, however little is known about the utilisation of emergency department by patients with complications of malaria. We describe clinical presentation, resource utilization, and outcomes of acutely ill patients with complications of malaria presenting to an urban emergency department (ED) in Tanzania.

Results: We screened 405 patients which physicians had a clinical suspicion or diagnosis of malaria at ED. We enrolled 184 (45.5\%) patients meeting WHO clinical and laboratory definition of malaria. The median age was 22 years (interquartile range 22-33 years), 105 (57\%) were male, and overall 124 (67.4\%) were self-referral. The use of insecticide treated nets (ITNs) in this group was 125 (67.4\%). Fever 125 (67.9\%), headache $56(30.4 \%)$ and general body malaise $41(22.2 \%)$ were the top three frequent complains, while tachycardia 83 (42.9\%) was the most frequent abnormal vital sign. Overall, 21 (11.4\%) patients had severe anaemia and 21 (11.4\%) had abnormal renal function test. In ED 121/184 (65.8\%) patients received antimalarial, 74/184 (40.2\%) received antibiotics, 6/184 (3.3\%) received antipyretic/analgesic and 5/20 (25\%) patients with severe anaemia received blood transfusion. Overall, 99/184 (53.8\%) patients were hospitalized, 3 (1.6\%) died at the ED, and the overall hospital morality was 3.8\%. Overall we found a substantial burden of patients with complications of malaria presenting in the largest public ED in Tanzania.
\end{abstract}

Keywords: Malaria complications, Emergency department, Africa, Tanzania

\section{Introduction}

Malaria is still a major health problem across the lower and middle income countries accounting for up to $40 \%$ of public expenditure in Africa [1]. In Africa about 300-500 million people suffer from malaria, of which millions of them progress to severe malaria. The Sub-Saharan Africa (SSA) is particularly most affected with malaria endemic, with estimates of $88 \%$ of global cases, mostly affecting children below the age of 5-years and pregnant women [2].

\footnotetext{
*Correspondence: rayayusuph@gmail.com

${ }^{1}$ Emergency Medicine Department, Muhimbili University of Health and Allied Sciences, P.O. Box 65001, Dar es Salaam, Tanzania

Full list of author information is available at the end of the article
}

In Tanzania, as in other SSA countries, malaria is among the top health problems, affecting particularly the children below age of 5-years and pregnant women. Over $90 \%$ of the population in Tanzania lives in Malaria zones, and $60 \%$ of the country population lives in the malaria endemic zones [3, 4]. In Tanzania, malaria ranks number three among the top 10 causes of deaths in all age groups, but with as significant effect in children under the age of five, accounting for up to mortality rate of $48 / 1000$ live birth in this age group [5].

The complications of malaria, including but not limited to hypoglycemia, anemia, acute kidney injury (AKI), acidosis, sepsis, hypoxia, shock, disseminated intravascular coagulopathy (DIC), respiratory distress and cerebral malaria have all been associated with poor outcomes [6]. In Tanzania most of health facilities lack the necessary 
resources to properly diagnose and manage acute malaria complication, some of the facilities lack basic laboratory tests to determine the acute complication of malaria [7] and this have caused the providers to rely mostly on the based on history and other clinical presentation, which may not be reliable in diagnosing the early acute complication of malaria, and hence most often patients presents or are referred late with irreversible complication of malaria [8].

The establishment of a full capacity Emergency Medicine Department at Muhimbili National Hospital (EMD$\mathrm{MNH}$ ) in Dar es salaam, Tanzania has provided an opportunity to improve and standardize care in the management of critically ill patients including acute complication of malaria. While most of these patients present in a critically ill stage and requires emergency interventions to abate death and improve long-term morbidity, the exact burden and outcome of patients with complications of malaria presenting to EMD remains unknown. We aimed to describe clinical presentation, resource utilization, and outcomes of acutely ill patients with complications of malaria presenting to an urban EMD in Tanzania.

\section{Main text \\ Methods \\ Study design}

This prospective study enrolled a consecutive sample of patients presenting to the EMD-MNH in Dar es salaam, Tanzania from 1 January 2017 to 31 September 2017.

\section{Study setting}

The EMD is a full capacity acute public emergency department of Muhimbili National Hospital (MNH), the National referral hospital located in Dar es Salaam, the commercial city of Tanzania. MNH has a 1500 bed capacity, receives an average of 1000-1200 outpatients per day, and the EMD has an annual volume of approximately 60,000 patients [9]. The department was opened in 2010, and is staffed by locally trained emergency medicine physicians who oversee care provided by medical officers, interns and residents. The department severs as the teaching unit for the only emergency medicine residency program in Tanzania [10].

\section{Study protocol}

The study investigator and research assistant prospectively screened and enrolled eligible patients using an electronic structured data sheet to record study information, including demographics, clinical presentation, management and EM diagnosis and final disposition. We followed up each patient to final hospital disposition, and recorded length of hospital stay, need for intensive care unit (ICU) or high dependency unit, final hospital diagnosis and clinical outcome (discharge or death).

\section{Data analysis}

Data from hand-written case report forms were transferred to Excel spreadsheet (Microsoft Corporation, Redmond, WA, USA), and imported to IBM SPSS Statistics v 23 for analysis. Demographic data is summarized by means and standard deviation (SD), we used Chi-square test to compare categorical variables, and Mann-Whitney U-test for comparison of continuous variables. In both comparisons, a two-tailed p-values of $<0.05$ was considered statistically significant.

\section{Results}

We screened $405(100 \%)$ patients who were clinically diagnosed to have malaria at EMD-MNH by the treating physician. Among 405 patients, 132 (32.5\%) tested positive for malaria (using either rapid diagnostic test or blood slide for malaria). In those who tested negative, $52(19.4 \%)$ presented with at least one feature of severe malaria as defined by the WHO and National guidelines (Additional file 1: Figure S1).

\section{Patient demographics}

Among 405 patients screened, 184 (45.4\%) were followed up (this includes 132 who tested positive for malaria, and 52 who tested negative for malaria but had at least features of severe malaria hence meeting the indication for initial malaria treatment). Among those followed up, $105(57.1 \%)$ were male, and the overall median age was 22 years [interquartile range (IQR) of 22-32 years]. Overall $124(67.4 \%)$ were self-referral from home, and the ITNs use among these patients was 125 (67.4\%) (Table 1).

\section{Patients' baseline variables and presenting complaints}

Tachycardia 83 (45.1\%) was the most frequent abnormal vital sign among enrolled patients; hypoxia $8(4.3 \%)$ was least. Fever 125 (67.9\%), headache 56 (30.4\%) and general body malaise $41(22.3 \%)$ were the top three presenting complaints (Table 1).

\section{Investigations ordered at EMD}

Of the 184 patients tested for malaria 132 (32.5) tested positive [by either rapid diagnostic malaria test (MRDT), blood slide for malaria parasite or both]. Among patients who received complete blood cell counts order 25 (13.5\%) had elevated white blood counts and 21 (11.4\%) had severe anaemia $(\mathrm{Hb}<7 \mathrm{~g} / \mathrm{dL})$ of who $5(2.7 \%)$ received blood transfusion in EMD (Additional file 2: Table S1). 
Table 1 Patient demographics

\begin{tabular}{|c|c|c|}
\hline \multirow[t]{2}{*}{ Demographics } & \multirow{2}{*}{$\begin{array}{l}\text { Number } \\
N=184 \\
n\end{array}$} & \multirow{2}{*}{$\begin{array}{l}\text { Percentage } \\
\%\end{array}$} \\
\hline & & \\
\hline \multicolumn{3}{|l|}{ Sex } \\
\hline Female & 79 & 42.9 \\
\hline Male & 105 & 57.1 \\
\hline \multicolumn{3}{|l|}{ Age group } \\
\hline 1 month to $<1$ year & 13 & 7.1 \\
\hline 1 year to $<5$ years & 29 & 15.8 \\
\hline 5 years to $<18$ years & 24 & 13.0 \\
\hline 18 years to $<60$ years & 111 & 60.3 \\
\hline$\geq 60$ years & 7 & 3.8 \\
\hline ITN use & 125 & 67.9 \\
\hline \multicolumn{3}{|l|}{ Referral status } \\
\hline Self referral & 124 & 67.4 \\
\hline Referred & 59 & 32.1 \\
\hline Missing & 1 & 0.5 \\
\hline Clinical characteristics & n (\%) & $95 \% \mathrm{Cl}$ \\
\hline \multicolumn{3}{|l|}{ Vital signs } \\
\hline Tachycardia $^{\mathrm{b}}$ & $83(45.1)$ & $38.1-52.3$ \\
\hline Febrile $\left(\mathrm{T}>37.5^{\circ} \mathrm{C}\right)^{\mathrm{a}}$ & $71(38.6)$ & $31.9-45.8$ \\
\hline Tachypneab $^{b}$ & $56(30.4)$ & $24.2-37.4$ \\
\hline Bradycardiab & $3(1.6)$ & $5.6-4.7$ \\
\hline Altered mental status & $6(3.2)$ & $1.5-6.9$ \\
\hline $\mathrm{SpO}_{2}<91 \%$ & $8(4.3)$ & $2.2-8.4$ \\
\hline \multicolumn{3}{|l|}{ Presenting complaints } \\
\hline Fever & $125(67.9)$ & $60.9-74.3$ \\
\hline Headache & $56(30.4)$ & $24.2-37.4$ \\
\hline General body malaise & $41(22.3)$ & $16.9-28.8$ \\
\hline Cough & $15(8.2)$ & $5.0-13.0$ \\
\hline Vomiting & $44(23.9)$ & $18.3-30.6$ \\
\hline Abdominal pain & $13(7.1)$ & $4.2-11.7$ \\
\hline Diarrhoea & $14(7.6)$ & $4.6-12.4$ \\
\hline Convulsion & $26(14.1)$ & $9.8-19.9$ \\
\hline Black urine & $2(1.1)$ & $0.3-3.9$ \\
\hline
\end{tabular}

a All measurements in axillary

b Appropriate for age

\section{Frequency and type of malaria complications}

Anaemia 21 (11.4\%) was the most frequent complication, followed by renal failure $15(8.2 \%)$ while disseminated intravascular coagulopathy (DIC) was the least frequent complication (Table 2).

\section{Patients' disposition and hospital outcomes}

Of the 184 malaria patients seen in the EMD, 99 (53.8\%) were hospitalized for inpatient care and 3 patients (1.6\%) died in the EMD. The overall in-hospital mortality rate
Table 2 Patient's rate of complication

\begin{tabular}{|c|c|c|}
\hline Complications & $\begin{array}{l}\text { Overall }(\mathrm{N}=184) \\
\mathrm{n} / \mathrm{N}(\%)\end{array}$ & $\begin{array}{l}95 \% \mathrm{Cl} \\
\%\end{array}$ \\
\hline Severe anaemia $(\mathrm{Hb}<7 \mathrm{~g} / \mathrm{dL})$ & $21(11.4)$ & $7.6-16.8$ \\
\hline Acute renal failure $^{a}$ & $15(8.2)$ & $5.0-13.0$ \\
\hline Respiratory distress ${ }^{b}$ & $8(4.3)$ & $2.2-8.3$ \\
\hline Hypoglycemia (<3 mmol/L) & $6(3.2)$ & $1.5-6.9$ \\
\hline Cerebral malaria & $6(3.2)$ & $1.5-6.9$ \\
\hline Shock & $3(1.6)$ & $0.6-4.7$ \\
\hline $\mathrm{DIC}$ & $1(0.5)$ & $0.1-3.0$ \\
\hline
\end{tabular}

Table 3 Patients' EMD outcome

\begin{tabular}{lcl}
\hline Outcome & $\begin{array}{l}\mathbf{N}=\mathbf{1 8 4} \\
\mathbf{n}(\%)\end{array}$ & $\begin{array}{l}\mathbf{9 5 \%} \mathbf{C l} \\
\mathbf{\%}\end{array}$ \\
\hline Discharged from EMD & $77(41.8)$ & $35.0-49.1$ \\
Admitted & $99(53.8)$ & $49.6-60.9$ \\
Died in EMD & $4(2.2)$ & $0.9-5.5$ \\
Overall hospital mortality $^{a}$ & $7(3.8)$ & $1.9-7.6$ \\
\hline
\end{tabular}

a Including EMD mortality

was $3.8 \%$ (Table 3 ). The median length of stay in hospital was 1 day (IQR $1-2)$ days.

\section{Discussion}

The establishment of a full capacity EMD at MNH in Tanzania manage provided an opportunity of early stabilization of acutely ill and injured patients, including those with acute complication of malaria. In this study over half of patients who were clinically suspected to have malaria by providers had neither laboratory evidence of malaria no features of severe malaria, a similar finding from what has been observed from other studies [11]. While we did not pursue further on to the treatment of this group of patients, we believe that maintaining the final EMD diagnosis of malaria, in absence of laboratory evidence and features of severe malaria, potentially put these patients in possibility of receiving antimalarial, contrary to the current national guidelines for diagnosis and management of malaria [12]. The rate of positive testing among those who were clinically suspected and tested for malaria was relatively higher compared to what has observed in other similar studies in our settings [11, 13], and we believe this might be attributed to the fact that most of these patients presents to this hospital after visiting several health facilities at district and regional levels, and hence their acuity of illness of illness is higher 
compared to similar studies in our settings. Interestingly, we found that majority of patients in our study population were adults above the age of 18 , and were self-referral from home with low compliance to utilization of insecticide treated net (ITN). The low compliance can be attributed to many factors as seen in previous studies [14], and this know to be associate with high malaria parasitaemia, and also frequent malaria in infection in most of malaria endemic regions [15]. Fever and headache accounted for over $90 \%$ of patients presenting complaint in those who tested positive for malaria. This is contrary to what has been seen in other studies that have shown viral infections to be the major cause of undifferentiated fever in naive outpatients [16]. We believe this might have been attributed to the differences in demographics of patients seen at this study (mostly adult) and the referral patterns of patients.

Nearly half of patients in this study had features of complications of malaria. Hypokalaemia requiring replacement was observed found in $20 \%$ of patients however only $1 \%$ of patient in this study received hypokalemia management at EMD or in the wards. While we didn't pursue the reasons for lack of treatment of hypokalemia, at the time of the study the department was quipped with management guidelines for hypokalemia, which calls for provision of supplemental potassium for these patients.

Anaemia was the most frequent complication of malaria observed in this study population, with over $10 \%$ of patients presenting with severe anaemia. Despite this presentation only one quarter of these patients received blood as part of care. This finding further complement the observation made by Shari et al. in a prospective observation of anaemic children presenting to same EMD in which only $23 \%$ of children with indications received transfusion [17]. None of patients with acute renal failure seen in this group received dialysis; all patients were managed conservatively until discharge, despite this, over $80 \%$ of these patients survived to hospital discharge. Less than $10 \%$ of patients were found to have cerebral malaria, unlike what has been observed in other studies of complications of malaria $[7,18]$. One-third of patients, who were eligible to receive antimalarial treatment, did not receive it while in the EMD and we could not verify whether these patients received antimalarial while in the wards. However, several factors might have contributed to this, including the fact that some of these patients might have already received initial treatment of malaria prior to referral to this EMD.

Most patients were admitted to the wards for the inpatient care, nine patients with uncomplicated malaria were also admitted to the wards, indicating the potential for other illnesses and complications that might have been associated with current malaria diagnosis. The observed mortality rate in our study low compared to other studies of malaria done in similar settings, and this is despite the relatively short duration of hospital stay compared to other settings [19].

\section{Conclusions}

There is a substantial burden of patients with complications of malaria presenting in the largest public ED in Tanzania. We have described their clinical presentation, management, outcomes and gaps in care provision. Future studies should focus on factors affecting delivery of appropriate care in patients with complications of malaria.

\section{Limitations}

This was a single-centre study and our results may not necessarily be generalizable to other settings, however the EMD at MNH is the largest tertiary referral hospital in Tanzania, and receives acutely ill and injured patients from all over the country.

\section{Additional files}

Additional file 1: Figure S1. Study flow diagram: patient enrollment results and outcomes.

Additional file 2: Table S1. Investigations ordered in the emergency department.

\section{Abbreviations}

AKI: acute kidney injury; ED: emergency department; EMD: Emergency Medicine Department; ICU: intensive care unit; ITN: insecticide treated net; $\mathrm{MNH}$ : Muhimbili National Hospital; MRDT: malaria rapid diagnostic test; WHO: World Health Organisation.

\section{Acknowledgements}

The authors wish to give her gratitude to the research assistants, study participants, EMD MNH Attending Physicians for their assistance in this project, and everyone who prayed for my success.

\section{Authors' contributions}

RY contributed to the conception and design of the study, acquired, analysed and interpreted the data, and drafted original manuscript and revised the manuscript. HRS contributed to conception and design of the study, data acquisition, entry, validation, and analysis and also critically revised the manuscript. PN contributed to the design of the study, data validation, and analysis and also revised the manuscript. JAM contributed to conception and design of the study, data validation, review, and analysis and also critically revised the manuscript. All authors read and approved the final manuscript.

\section{Funding}

This was a non-funded project; the principal investigators used their own funds to support the data collection and logistics.

Availability of data and materials

The dataset supporting the conclusion of this article is available from the authors on request.

\section{Ethics approval and consent to participate}

The institutional review board and the committee on research of the Muhimbili National Hospital (MNH) approved the study protocol. MNH administration 
provided permission for in-hospital follow-up. Written informed consent was obtained from patients, and patient parents or guardians when a patient was a child below the age of 18 years.

\section{Consent for publication}

Not applicable.

\section{Competing interests}

The authors declare that they have no competing interests.

\section{Author details}

${ }^{1}$ Emergency Medicine Department, Muhimbili University of Health and Allied Sciences, P.O. Box 65001, Dar es Salaam, Tanzania. ${ }^{2}$ Emergency Medicine Department, Muhimbili National Hospital, Dar es Salaam, Tanzania.

Received: 12 March 2019 Accepted: 13 June 2019

Published online: 18 June 2019

\section{References}

1. Malaria \& medicines. Medicines for malaria venture. http://www.mmv org/malaria-medicines?gclid=CjwKEAjwiru9BRDwyKmR08L3iSOSJA BN8T4vy3Y2UNNRRp9QmQ6GKtWJOAQH-Mhhgqbk0QfcnDE0RoC_ Qvw_wcB. Accessed 13 Aug 2016.

2. Summary of the world malaria report 2015. http://apps.who.int/iris/ bitstream/10665/205224/1/WHO_HTM_GMP_2016.2_eng.pdf?ua=1. Accessed 13 Aug 2016.

3. Tanzania Malaria Operational Plan FY 2016. https://www.pmi.gov/docs/ default-source/default-document-library/malaria-operational-plans/fy16/ fy-2016-tanzania-malaria-operational-plan.pdf?sfvrsn=4. Accessed 22 Dec 2016.

4. Mboera LE, Kitua AY. Malaria epidemics in Tanzania: an overview. Afr J Health Sci. 2001;8(1-2):17-23.

5. CDC Global Health-Tanzania. https://www.cdc.gov/globalhealth/count ries/tanzania/. Accessed 24 Oct 2016.

6. Malaria: life-threatening complications-topic overview. WebMD. http:// www.webmd.com/first-aid/tc/malaria-life-threatening-complicationstopic-overview. Accessed 24 Oct 2016.

7. Bartoloni A, Zammarchi L. Clinical aspects of uncomplicated and severe malaria. Mediterr J Hematol Infect Dis. 2012;4(1):e2012026.
8. Tanzania service provision assessment survey 2014-2015 [SPA22]. https:// dhsprogram.com/pubs/pdf/SPA22/SPA22.pdf. Accessed 22 Dec 2016.

9. Reynolds T, Sawe HR, Lobue N, Mwafongo V. Most frequent adult and pediatric diagnoses among 60,000 patients seen in a new urban emergency Department in Dar Es Salaam, Tanzania. Ann Emerg Med. 2012;60(4):S39

10. Reynolds TA, Mfinanga JA, Sawe HR, Runyon MS, Mwafongo V. Emergency care capacity in Africa: a clinical and educational initiative in Tanzania. J Public Health Policy. 2012;33(S1):S126-37.

11. Osowicki J, Curtis N. Causes of fever in outpatient Tanzanian children. N Engl J Med. 2014;370(23):2242-3.

12. WHO. Guidelines for the treatment of malaria, 2nd ed. WHO. http:// www.who.int/malaria/publications/atoz/9789241547925/en/index.html. Accessed 26 Mar 2013.

13. D'Acremont V, Kilowoko M, Kyungu E, Philipina S, Sangu W, Kahama-Maro , et al. Beyond malaria_causes of fever in outpatient Tanzanian children. N Engl J Med. 2014;370(9):809-17.

14. Atieli HE, Zhou G, Afrane Y, Lee M-C, Mwanzo I, Githeko AK, et al. Insecticide-treated net (ITN) ownership, usage, and malaria transmission in the highlands of western Kenya. Parasites Vectors. 2011;18(4):113.

15. Iwuafor AA, Egwuatu CC, Nnachi AU, Ita IO, Ogban Gl, Akujobi CN, et al. Malaria parasitaemia and the use of insecticide-treated nets (INTs) for malaria control amongst under-5 year old children in Calabar, Nigeria. BMC Infect Dis. 2016;16:151

16. Prasad N, Murdoch DR, Reyburn H, Crump JA. Etiology of severe febrile illness in low- and middle-income countries: a systematic review. PLoS ONE. 2015;10(6):e0127962.

17. Shari CR, Sawe HR, Murray BL, Mwafongo VG, Mfinanga JA, Runyon MS. Emergency blood transfusion practices among anaemic children presenting to an urban emergency department of a tertiary hospital in Tanzania. BMC Hematol. 2017;10(17):19.

18. Trampuz A, Jereb M, Muzlovic I, Prabhu RM. Clinical review: severe malaria. Crit Care. 2003;7(4):315-23.

19. Melzer M. Outpatient treatment of falciparum malaria is possible. BMJ. 2006;333(7564):397-8.

\section{Publisher's Note}

Springer Nature remains neutral with regard to jurisdictional claims in published maps and institutional affiliations.
Ready to submit your research? Choose BMC and benefit from:

- fast, convenient online submission

- thorough peer review by experienced researchers in your field

- rapid publication on acceptance

- support for research data, including large and complex data types

- gold Open Access which fosters wider collaboration and increased citations

- maximum visibility for your research: over $100 \mathrm{M}$ website views per year

At BMC, research is always in progress.

Learn more biomedcentral.com/submissions 